\title{
EDUCAÇÃO AMBIENTAL NA MITIGAÇÃO DOS EFEITOS CLIMÁTICOS NO DISTRITO DE CHÓKWÈ EM MOÇAMBIQUE
}

\author{
Munossiua Efremo Macorreia ${ }^{1}$
}

RESUMO: O presente estudo, teve como objetivo Promover o debate sobre o que podemos fazer para amenizar os efeitos climáticos em ChókwèMoçambique, focando na Educação Ambiental, na conservação, na redução das emissões provocadas por desmatamentos, sensibilizando as comunidades locais para a reposição das plantas nos locais com maior degradação e investirem no transporte público, usando menos viaturas individuais. Baseado nos resultados do questionário foi feito um levantamento bibliográfico de natureza qualitativo, quantitativo, exploratório e descritivo. Trabalhámos com uma amostra de 48 pessoas. A pesquisa, comportou uma busca de diversas informações relacionadas ao tema, na perspectiva de compreender claramente as causas que originam os efeitos climáticos em Chókwè, gerando consequências nas relações sociais, nos níveis populacionais, no estoque de alimentos, na extinção de certas espécies animais e florestais, em novas doenças, nos deslocamentos populacionais e ambientais, favorecendo a participação dos aprendizes como agente ativo do processo na regulação das relações sociais capaz de ajustar a conduta, nos padrões ecologicamente sustentáveis e adequados à mitigação e adaptação aos efeitos climáticos. Para isso, foram desenvolvidos diversos debates junto ao público-alvo da pesquisa (os produtores de carvão vegetal, vendedores da rua, motoristas de minibus, aprendizes do Instituto Agrário de Chókwè, sobretudo professores), criando estratégias inovadoras e motivadoras em resposta às mudanças atuais. Como resultados das discussões verificamos que o Instituto não possui nenhum programa curricular que tenha integrado a Educação Ambiental na mitigação dos efeitos climáticos, não estando em conformidade com a legislação Moçambicana.

Palavras-Chaves: Educação Ambiental; Efeitos Climáticos; Sensibilização.

${ }^{1}$ Professor da Universidade Save, Doutorado em projeto com área de pesquisa Meio Ambiente, Qualidade e Prevenção. E-mail: efremomunossiua@yahoo.com.br 
Abstract: The present study aimed to promote the debate about what we can do to mitigate the climatic effects in Chókwè-Mozambique, focusing on Environmental Education, conservation, reducing emissions caused by deforestation, sensitizing local communities to the replacement of plants in places with greater degradation and invest in public transport, using less individual vehicles. Based on the results of the questionnaire, a bibliographic survey of a qualitative, quantitative, exploratory and descriptive nature was made. We worked with a sample of 48 people. The research involved a search for various information related to the theme, in order to clearly understand the causes that cause the climatic effects in Chókwè, generating consequences for social relations, population levels, food stocks, the extinction of certain animal species and forest, in new diseases, in population and environmental displacements, favoring the participation of apprentices as an active agent in the process of regulating social relations capable of adjusting conduct, in ecologically sustainable standards and suitable for mitigation and adaptation to climatic effects. For this, several debates were developed with the target audience of the research (charcoal producers, street vendors, minibus drivers, apprentices of the Agrarian Institute of Chókwè, especially teachers), creating innovative and motivating strategies in response to current changes. As a result of the discussions, we verified that the Institute does not have any curricular program that has integrated Environmental Education in the mitigation of climatic effects, not being in compliance with Mozambican legislation.

Keywords: Environmental Education; Climate Effects; Awareness.

\section{Introdução}

A degradação ambiental, é hoje uma das maiores preocupações dos governos e da sociedade em geral e constitui grande desafio para toda comunidade do planeta terra, pois a elevação da temperatura média que se vive nos últimos tempos na superfície terrestre, devido a maior pressão acelerada humana sobre os recursos naturais, poderá resultar na troposfera mudanças climáticas, milhões de toneladas de dióxido de carbono $\left(\mathrm{CO}_{2}\right)$, metano $\left(\mathrm{CH}_{4}\right)$ e nitrogênio, destruindo áreas consideráveis de florestas tropicais e a extinção de certas espécies animais e florestais. Estes efeitos climáticos, podem ter sua origem tanto natural quanto humano (Oliveira, Silva, Henriques, 2009, p. 946-962).

Em face dessa problemática, a Educação Ambiental ainda está longe de ser uma atividade reconhecida e desenvolvida por todos os envolvidos, pois no mundo atual ainda prevalece certos países, principalmente as grandes potências econômicas, preocupadas na fabricação das armas nucleares, aumentando à proliferação ambiental já existente desde do século XVIII com revolução industrial e o desenvolvimento da globalização que se vive no planeta terra. 
Assim, no período de 1970 à 2004, verificou um aumento de $80 \%$ das emissões gases de efeito estufa, principalmente do gás carbônico. Até 2050 as emissões devem sofrer uma redução de $50 \%$ a $85 \%$, a partir dos dados quantitativos de 2000. Os custos desses esforços seriam de $3 \%$ do PIB mundial em 2030 (PAINEL INTERGOVERNAMENTAL SOBRE MUDANÇAS CLIMÁTICAS, 2007).

É nesta vertente, que o Painel Intergovernamental sobre os efeitos Climáticos (IPCC, 2007), no seu relatório indica que até 2100 existe a possibilidade de aumento de $1,8^{\circ} \mathrm{C}$ até $4^{\circ} \mathrm{C}$ da temperatura média do planeta.

Essa situação, torna cada vez mais complicada se o homem até 2100 , não mudar o seu comportamento insustentável em relação ao meio ambiente. Pois, essa alta temperatura na pior das previsões pode chegar a $6,4^{\circ} \mathrm{C}$, aumentando o nível dos oceanos $18^{\circ}$ a $59^{\circ}$ centímetros; As chuvas poderão atingir uma percentagem de 20\%; O gelo do Pólo Norte poderá ser completamente derretido no verão; $O$ aquecimento da Terra não será homogêneo e será mais sentido nos continentes que no oceano e o hemisfério norte será mais afetado que o sul, provocando uma redução efetiva na disponibilidade de alimentos e levar a fome a milhões de pessoas, aumentando gradualmente as desigualdades regionais (PAINEL INTERGOVERNAMENTAL SOBRE MUDANÇAS CLIMÁTICAS, 2007).

Portanto, fica bem claro que essa situação tem a sua origem na igonorância do homem, pensando que a natureza é o seu mercado com recursos naturais incabábeis, realizando sua atividade de queima de combustível fósseis, o avanço tecnológico da agricultura com o uso excessivo dos fertilizantes e o desmatamento, ultrapassando a capacidade de suporte do meio ambiente natural (LÜKMAN, 2006, p. 55-67).

Indo ao encontro das necessidades ambientais mundiais, de acordo com a situação verificada acima, surgem-nos o seguinte problema de investigação: De que forma a Educação Ambiental, pode contribuir para conscientização ambiental, desenvolvendo proposta da política pública de Educação Ambiental sobre os efeitos climáticos, constituindo novas escolhas no estilo de vida, mudanças de atitudes e valores no uso e apropriação dos recursos naturais? Assim, este estudo tem como objetivo: Promover o debate sobre o que podemos fazer para amenizar os efeitos climáticos, focando na Educação Ambiental, na conservação, na redução das emissões provocadas por desmatamentos e queimadas, sensibilizando as comunidades locais na reposição das plantas nos lugares que apresentam maior degradação e investirem no transporte público, usando menos viaturas individuais.

É nesta contextualização, que a Educação Ambiental deve ser vista como o único instrumento educativo. Pois, ela quando bem realizada, "leva consigo a mudança do comportamento, atitudes e valores de cidadania das grandes potências económicas, porque implica levar o conhecimento e a realidade próxima dos problemas ambientais, desenvolvendo uma consciência 
ambiental que faça a diferença no futuro dos seres vivos que habitam na terra planetária" (BRASIL, 1998, p.182).

Portanto, já chegou a hora de cada um fazer a sua parte para salvar o planeta terra, refletindo as novas maneiras de convivências sustentáveis, ensinado os aprendizes a partir da sua realidade prévia que "os problemas ambientais, não possuem fronteiras delimitadas, compreendendo desde cedo que a Educação Ambiental não é uma disciplina suplementar que se soma aos programas curriculares existentes, exige a interdisciplinaridade, indispensável para poder transformar às disciplinas que deverão gerar os conteúdos adequados de novas temáticas ambientais" (GONZÁLEZ-GAUDIANO, 2005, p. 123).

Assim, a Educação Ambiental deve procurar colocar os aprendizes em situações que sejam formadores, diante da agressão dos efeitos climáticos, desenvolvendo "novas tecnologias limpas e expandir reservatórios naturais para cultivar o verde, estabelecendo políticas ambientais apropriadas, que possibilitam as mudanças de hábitos, costumes de uso sustentável e reduzir as diferenças sociais, garantindo assim, a permanência dos recursos naturais em condições que assegure às gerações futuras sobrevivência na Terra planeta" (MARENGO, 2006).

Nesta vertente, a escola deve promover a Educação Ambiental em salade-aula em todos os níveis de escolaridades, mostrando aos aprendizes sua importância no contexto ambiental, possibilitando a construção de um conjunto de ações comuns compromissadas com o aquecimento global, o degelo das calotas polares, a reciclagem, o calor e o frio em demasiado, a falta de água, dentre outros.

Face a isso, consta que a Dinamarca e a Austrália, desenvolveram nos seus programas curriculares a Educação de Desenvolvimento Sustentável, visando construir os conhecimentos específicos relacionados à Educação Ambiental no contexto dos efeitos climáticos (CHAMBERS, 2009, p. 359).

No Continente Asiática, a China também desenvolveu os currículos escolares, incluindo os conhecimentos específicos de Educação Ambiental no âmbito dos efeitos climáticos, principalmente no ensino básico, com vista a formação das crianças e adolescentes (HAN, 2015, p. 62-77).

É neste âmbito, que as questões da Educação Ambiental no âmbito dos efeitos climáticos, constituem maior desafio de todos os residentes da cidade de Chókwè, bem como, a humanidade em geral, articulando normas jurídicas capazes de enfrentar o comportamento insustentável, prevendo ações jurídicas de adaptação, com consonância realidade natural, sensibilizando a comunidades escolar para a construção de conhecimento comprometedor com o presente e com o futuro das nossas gerações vindouras. 


\section{Contextualização}

Os problemas ambientais ocorrem em nível global, no entanto, também ocorrem na escala local, quer dizer, estão interligados, por isso os riscos associados aos efeitos climáticos, não são exclusivamente dos Países pobres, mas sim global e ao mesmo tempo localizados. A título de exemplo, no ano de 2003 a Europa viveu uma onda de calor causado 40 mortos e a seca no oeste da Amazónia em 2005 (KOSATSKY, 2005).

Assim, a Educação Ambiental, têm-se popularizado no mundo desde os anos 80 , desenvolvendo modelos que permitam explicar as causas sobre a origem de desmatamento e queimadas, destruição de camada de ozôno e ecossistemas, colocando em perigo o futuro do planeta terra (GUIMARÃES, 1995).

É diante desta reflexão, que Jacobi et al (2011), reforça o pensamento do Guimarães (1995), ao afirmar que:

as questões dos efeitos climáticos, constitui um subcapítulo da educação e da crise socioambiental contemporânea e que só é possível acercar-nos delas através das conexões políticas, ecológicas, culturais e debates entre vários pesquisadores ligados as questões ambientais, esclarecendo as causas, consequências e medidas de mitigação.

A partir desta contextualização, a Educação Ambiental começou a receber diversas definições. Dentre elas, a do Loureiro (2009, p. 25-26), Educação Ambiental é:

um processo permanente que possibilita o diálogo com as questões ambientais, construindo conhecimentos que tornem inovadores na mudança de valores, atitudes e comportamentos, partindo da interdisciplinaridade, envolvendo todos os atores com consciência local e planetária, formando pessoas que respeitem a autodeterminação dos povos e a soberania das nações.

Aliando-se, também à proposta de Gadotti (2001, p.98), vem completar a ideia do Loureiro (2009, p. 25-26), ao dizer que:

a Educação Ambiental é um instrumento indispensável no seio da sociedade. Pois, é a partir dela que o indivíduo carrega consigo todas as formas de vida com as quais compartilhamos este planeta, respeitando a solidariedade, a igualdade e os direitos humanos, valendo-se de estratégias que envolve 0 sentimento, o amor, o ter prazer, a solicitude com que os pais educam os seu filhos, reconhecendo que somos parte integrante do planeta terra e que podemos viver com ela em harmonia sem conflitos. 
Portanto, as intuições de educação, principalmente à do ensino técnico profissional, deve ensinar os aprendizes que "as práticas educativas devem contribuir para a mitigação das causas dos efeitos climáticos, estabelecendo conceitos como favoráveis à preservação da vida, a justiça social e a sustentabilidade global através da responsabilidade assumida pela Educação Ambiental' (LOUREIRO; AZAZIEL; FRANCA, 2003).

Neste contexto, a escola tem a obrigação não apenas de despertar maior interesse aos aprendizes para o desenvolvimento da consciência ambiental deste o nível-escolar até pós-graduação sobre a temática da problemática ambiental, mas também constitui um palco de atuação prática dos novos valores que são colocados pela Educação Ambiental, alertando que:

muitos projetos em Educação Ambiental estão sendo desenvolvidos de forma pouco sistematizada apesar da palavra da Educação Ambiental ser de conhecimento da maioria, seu significado ainda é pouco claro entre os educadores e, principalmente, entre a população em geral, sendo muitas vezes confundida com a ecologia (GUIMARÃES, 1995).

Para isso, torna indispensável convidar os órgãos governamentais, pais e encarregados de educação, representantes dos Ministério de Ciência e Tecnologia, ensino Superior e Técnico Médio Profissional, de Educação e Desenvolvimento Humano e a da Terra Ambiente e Desenvolvimento Rural, para em conjunto perceber a partir da percepção ambiental dos aprendizes, professores e as comunidades em gerais as causas motivadoras da degradação do meio ambiente na região em estudo, possibilitando a estruturação de ções direcionadas para a alcançar o avanço tecnológico que favorece a regeneração dos recursos naturais.

\section{Efeitos climáticos no contexto moçambicano}

Moçambique, é um País do continente Africano localizado na costa oriental, a sul do equador na região da África Austral. Com uma superfície de 799.380 e encontra-se exposto aos riscos dos desastres naturais, devido a sua localização na região de convergência intertropical, tornando-o vulnerável a ventos extremos de origem meteorológico, causando vários impactos climáticos, tais como: seca, cheias, ciclone tropical (FAO, GOVERNO DE MOÇAMBIQUE, 2009).

Assim, o distrito de Chókwè sendo parte do País, não está isento deste fenómeno. Alguns exemplos das informações-chaves dos efeitos climáticos: No dia 14 de março de 2019, o Ciclone tropical IDAI, de categoria 4 atingiu a cidade da Beira, localizada no centro de Moçambique com ventos fortes correspondente a $180-220 \mathrm{~km} / \mathrm{h}$ e chuvas intensas mais de $200 \mathrm{~mm}$ em 24 horas, provocando transbordo de rios, com as águas das cheias a atingirem cerca de dez metros, destruindo diversas culturas e danos generalizados as infraestrutura importantes (Instituto Nacional de Gestão de Calamidade-INGC, 15 de Abril de 2019).

revista brasileira educação ambiental 
O mesmo Instituto Nacional de Gestão de Calamidade, indica que no ano 2000, o sul de Moçambique principalmente a cidade de Chókwè, registou cheias que mataram centenas de milhares de pessoas e destruíram diversas infraestruturas. Treze anos depois, a história repete-se. Na província de Gaza, a cidade de Chókwè ficou debaixo de água (Figura 1):

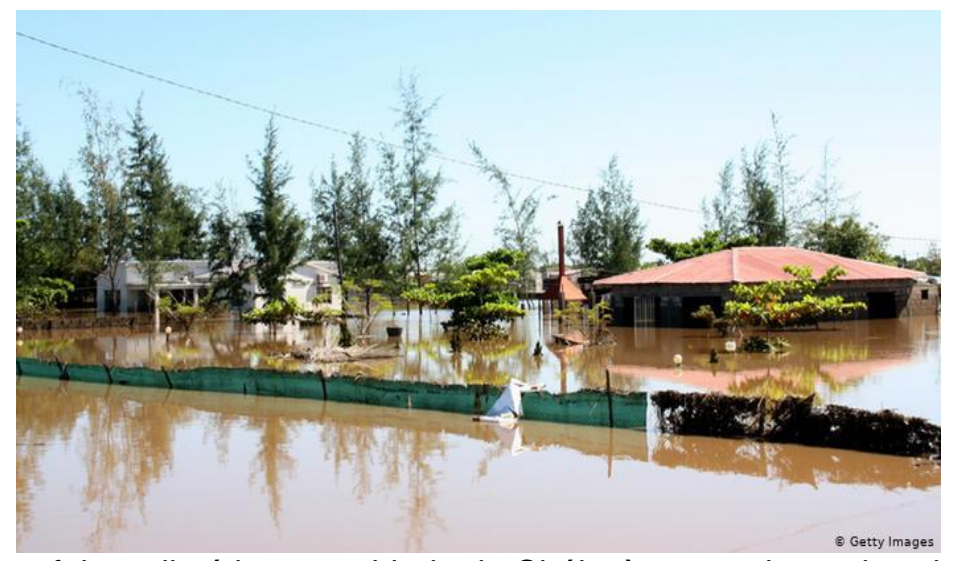

Figura 1: llustra os efeitos climáticos na cidade de Chókwè, proveniente das cheias do ano 2013. Fonte: https://www.dw.com/pt-002/cheias-treze-anos-depois-trag\%C3\%A9dia-volta-amo\%C3\%A7ambique/a-16578821

Neste contexto, os efeitos climáticos que assolam o País, contrariam os objetivos do Governo local, nacional e dos parceiros que se lidam com à luta pela erradicação da pobreza absoluta.

A situação torna-se mais complicadas, devido a insuficiência de organismos internacionais capazes de mediar as relações entre as nações e destas com as grandes corporações sobre questões globais, como é o caso do aquecimento global. A Organização das Nações Unidas, são os únicos recursos disponíveis, mas devido às assimetrias de poder no contexto mundial tem revêlado claramente a insuficiência de gerir as situações nos momentos de crise.

Assim, em resposta aos principais fatores de vulnerabilidades dos efeitos climáticos acima identificados, sustenta-se que é da responsabilidade do governo local, e Organição não-governamental (ONG), reiterar que a prioridade nacional é a adaptação e redução de desastres climáticas, deva ser assumida como um compromisso do quadro CQNUMC (Convenção Quadro das Nações Unidas para as Mudanças Climáticas). Onde são identificadas as oito áreas estratégicas de intervenção:

1). Redução de risco dos efeitos climáticos; 2) Recurso hídrico; 3) Agricultura, pesca, segurança alimentar e nutricional (NAN); 4) Proteção social; 5) Saúde; 6) Biodiversidade; 7) Floresta e fauna-bravia; e 8) Infraestrutura.

Como consta dos postulados oito acima, o nosso interesse fundamental está ligado ao primeiro (Redução de risco dos efeitos climáticos), mesmo havendo uma interligação intrínseca entre os outros restantes, pois esta problemática reflete-se em todas outras dimensões acima destacadas, mas importa salientar que no caso do estudo em epígrafe, urge trazer estratégia 
para garantir que haja um ambiente saudável na comunidade em estudo, como solução aplicável às demais que passam pela mesma problemática em Moçambique e no mundo em geral.

Face a isso, consta também que as estratégias de intervenção previstas no quadro da Convenção Quadro das Nações Unidas para as Mudanças Climáticas (CQNUMC), não são observadas, devido a falta de um sistema eficaz de aviso prévio sobre a componente climatérica que têm contribuindo, basicamente, para os efeitos climáticos regionais e locais da área em estudo, especialmente nas comunidades rurais do distrito de Chókwè em que as informações climáticas são inexistentes, incluindo infra-estruturas de partilhas de informação sobre ocorrência de eventos extremos como no caso das estações meteorológicas e rádios comunitários.

Assim, o sistema de aviso prévio de maior relevância com vista a minimizar os efeitos climáticos, deveria prestar maior atenção na mobilização de fundos para estabelecimento das infra-estruturas de partilha de informação climática pelo Governo ao nível Nacional, Regional, Provincial, incluindo o Distrital, pois a população lá existente são parte desta sociedade, por isso devem ser formadas e informadas sobre estes riscos, atempadamente, envolvendo outros parceiros que têm conhecimentos profundos sobre a matéria de sensibilização comunitária, como: (Sector Privado, ONG, Organização da Sociedade Civil, Doadores, entre tantos outros).

Assim, a Educação Ambiental, deve ser realizada constantemente, tanto pela educação não formal (em espaços públicos), bem como, pela educação formal (em espaços escolares) ou informal (pela mídia), capacitando permanentemente os aprendizes, sobretudo os docentes para o enfrentamento e adaptação aos efeitos climáticos.

\section{Resultados e discussões}

Para o desenvolvimento deste trabalho, pautamos pelo levantamento bibliográfico de natureza qualitativo, quantitativo, exploratório e descritivo fundamentada na técnica de análise de conteúdo, que segundo Bardin (1977, p. 31), define:

como um instrumento com maior rigor, mais marcado por grande disparidade de forma adaptável a um campo de comunicação, seguindo vários caminhos, inclusive a margem da pesquisa de natureza quantitativa ou qualitativa.

Diante disso, foi realizado um questionário a partir de uma amostra de 48 pessoas, subdivididas de acordo o grupo-alvo (produtores de carvão, motoristas de minibus dos passageiros, vendedores da rua, aprendizes e professores). 
Numa primeira fase, foi aplicado o questionário, visando avaliar o diagnóstico do conhecimento dos aprendizes sobre percepção, ideias, crenças e conhecimento referente a relevância da Educação Ambiental dentro do contexto das causas fundamentais da origem dos efeitos climáticos, buscando contribuir para a informação e sensibilização sobre aspectos envolvidos na conservação do meio ambiente.

Baseado nos resultados do questionário, foi trabalhada a segunda etapa com os professores do Instituto Agrário de Chókwè, debatendo-se diversos temas tais como: a) Meio ambiente; b) Educação Ambiental; c) origem dos efeitos climáticos; d); e) Sensibilização das comunidades locais e escolares quanto à questão da mitigação dos efeitos climáticos como alterações causadas pelos seres humanos, sendo esses os principais causadores, como apontados pelo Painel Intergovernamental sobre Mudanças Climáticas em 2007.

$\mathrm{Na}$ terceira etapa, buscamos junto aos produtores de carvão, motoristas de minibus dos passageiros e vendedores da rua, as informações que possam ajudar a preservação e utilização sustentável dos recursos naturais, no qual as comunidades locais tomam consciência do seu meio ambiente e adquirem conhecimentos e a determinação que as tornam estar preparadas para a mitigação dos efeitos climáticos.

Como resultado, verificamos que o Instituto Agrário de Chókwè, não possui nenhum programa curricular que tenha integrado a Educação Ambiental na mitigação dos efeitos climáticos, não estando em conformidade com a legislação Moçambicana.

É neste sentido, que este trabalho poderá contribuir efetivamente para amenizar os efeitos climáticos ambientais locais, adotando propostas que proporcionem a redução das emissões de gases de efeito de estufa. Assim, houve discussões, variações de perguntas e respostas conforme os Gráficos 1,2 , e 3 .

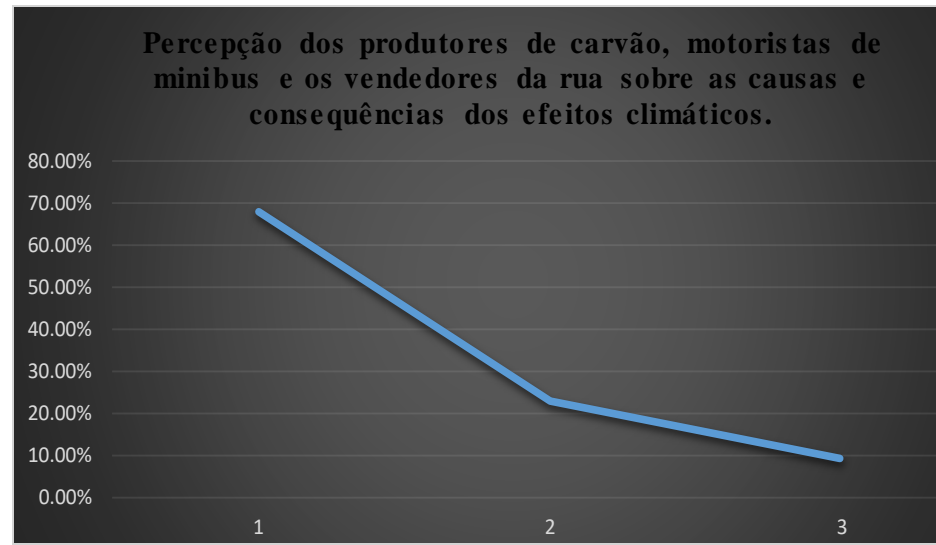

Gráfico 1: Percepção dos produtores de carvão, motoristas de minibus e vendedores de rua sobre as causas e consequências dos efeitos climáticos. 
Nota-se que $68.18 \%$ dos produtores de carvão responderam que realizam desmatamento, aumentando a problemática dos efeitos climáticos, visando a limpesa dos campos para as práticas agrícolas, pastagens, abertura de caminhos para facilitar a circulação das pessoas, corte das estacas para construções de habitações; $22.73 \%$ dos vendedores da rua, responderam claramente que os efeitos climáticos, fazem sentir com maior realce nos Países em desenvolvimento, pois como é possível conservarmos o meio ambiente em Moçambique, enquanto os Países desenvolvidos exigem a utilização contínua de tais recursos de forma a promover o crescimento econômico? A título de exemplo: Os dados divulgados em 2008, mostram que "a China é responsável por $23 \%$ do total mundial das emissões de gases do efeito estufa; os Estados Unidos são responsáveis por $20 \%$ das emissões totais e outros Países" (VIOLA, 2010), originando perda de capacidade agrícola, de infraestruturas, de mortes por ondas de calor, por ondas de frio e inundações. 9.09\% dos motoristas de minibus de passageiros, afirmaram que como mitigar os efeitos climáticos enquanto o governo moçambicano. continua a importar maior quantidade de viaturas no Japão, Estados Unidos da América etc., não só estão cansadas, mas também desfalcadas de alguns dispositivos essenciais para a redução de emissões, contribuindo para a qualidade de ar, aumentando o dióxido de carbono (CO2), principalmente nas grandes cidades tais como: Maputo, Beira, Nampula etc.

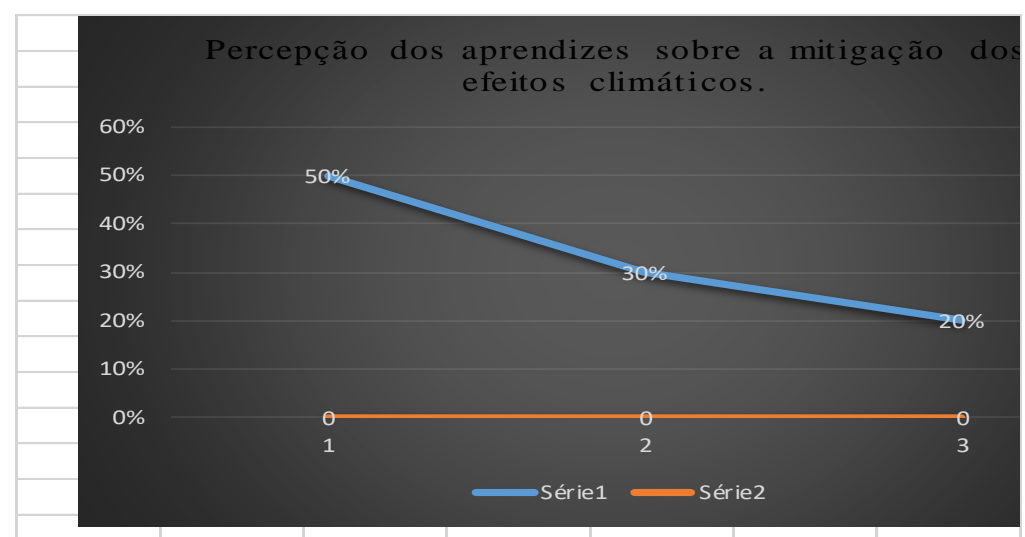

Gráfico 2: Percepção dos aprendizes sobre a mitigação dos efeitos climáticos.

Nota-se que $50 \%$ dos aprendizes no geral mostram que as causas da origem dos efeitos climáticos parecem ainda distante de serem compreendas por todos. Isso é apenas uma impressão, na medida em que graduamos os nossos cursos sem ouvir falar ou conhecer a relevância da Educação Ambiental na mitigação do uso insustentável. Assim, nos tempos de hoje as consequências estão cada vez mais acrescidas, visíveis e mais próximas para o aquencimento global. 30\% Dos aprendizes da turma "D do primeiro ano do Instituto", acreditam que a mitigação dos efeitos climáticos no distrito, depende da inclusão dos conteúdos que versam a Educação Ambiental nos programas curriculares do ensino técnico profissional, de forma clara e compreensível, possibilitando a mediação dos professores na educação dos aprendizes sobre 
os padrões aceitáveis de comportamento ambiental sustentável, atenuando a problemática dos efeitos climáticos pela prática de uma educação específica interdisciplinar, construindo conhecimentos climáticos, ambientais, geográficos, biofísicos, entre outros. 20\% Aprendizes da Turma "E do segundo ano", acreditam que uma das soluções desta problemática ambiental, é a vontade política na introdução do "livro do aluno contendo conteúdos dos efeitos climáticos, cabendo ao professor especializado na área ter uma atenção quanto a seleção dos conteúdos apropriados e sua utilização em sala de aula" (ROMANATTO, 2004).

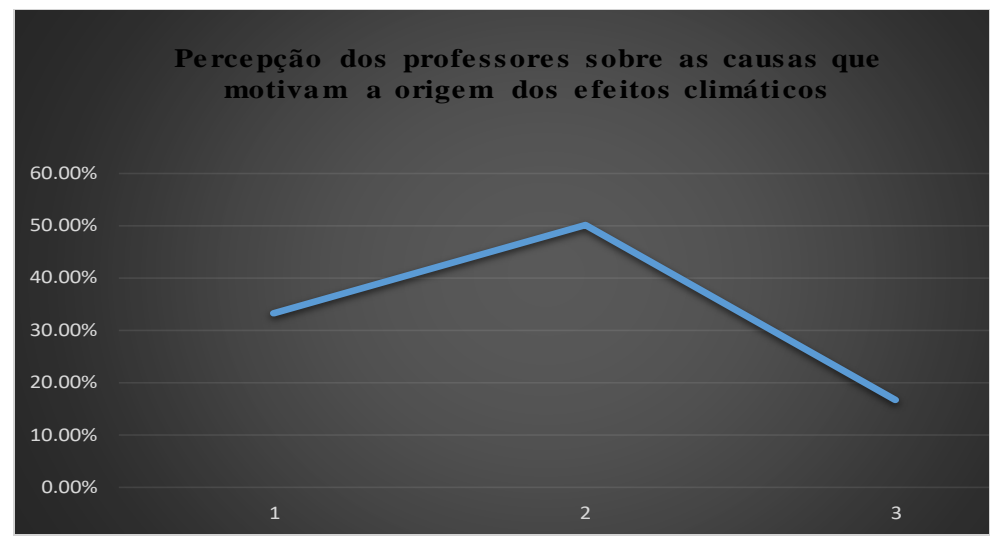

Gráfico 3: Percepção dos professores sobre as causas que motivam a origem dos efeitos climáticos.

Nota-se que $33.33 \%$ Dos professores que lecionam o segundo ano do nível médio do Instituto, mostram claramente que Hoje, os efeitos climáticos no município da cidade de Chókwè, justificam-se pelo crescimento populacional que o distrito vive atualmente, a urbanização desordenada, a ocupação de áreas de riscos, o desmatamento crescente, visando a extração de madeira que posteriormente é vendida a preços altos no Continente Asiático, concretamente na China, produção de carvão vegetal, vendido localmente e na capital do País-Maputo, expansão agrícola e pecuária no vale do rio Limpopo. $50 \%$ afirmaram o contrário, logo esses dados levam-nos a concluir que a situação torna cada vez mais complicada, devido a falta de política pública transversal capaz de disseminação da informação sobre as consequência dos efeitos climáticos, a educação, o debate e a participação social na construção de modelo de desenvolvimento em busca de um estilo de vida sustentável; $16.67 \%$ Mostra que a resolução desta problemática, é urgente que os governantes locais, regionais, internacionais, as Organizações nãoGovernamentais (ONGs), e outros, devem criar metodologias participativas na obtenção de conhecimento formal e não formal relacionado à mudança nos padrões de atividades humanas, estabelecendo metas e normas de conservação ambiental em prol da mitigação dos efeitos climáticos.

Assim, fica bem claro que o problema ambiental que assola o distrito, bem como o mundo em geral, deriva-se da ignorância do homem, provocando pelas formas de ocupação do solo, construções desordenadas, a retirada da 
cobertura vegetal para vários fins, o uso tecnológico que prolifera maior quantidade de emissões de gases do efeito estufa.

Portanto, há necessidade urgente de incentivar os investidores a avaliar as emissões potenciais de gases de efeito de estufa, nos projetos de investimentos tecnológicos e fontes de energia limpas, melhorando o bem-estar das comunidades locais dos moçambicanos, partindo da implementação da Lei do meio ambiente (Lei 20/97, de 1 de Outubro); Decreto $n^{0}$ 30/2012, de agosto da lei $n^{0} 11 / 2003$, de 25 de março Lei da floresta e o Decreto $n^{0} 25 / 2011$ de 15 de julho regulamento relacionado ao processo de auditoria ambiental, aprovado pelo decreto $\mathrm{n}^{0} 32 / 2003$ de 12 de agosto.

No entretanto, a escola é condição fundamental para a promoção da cidadania e despertar o interesse dos formandos pelos diversos assuntos voltados para a questão ambiental. Pois, os problemas identificados durante o processo da pesquisa podem servir de referências para novas soluções. $E$ ao mesmo tempo indicam novos horizontes e possibilidades didático-pedagógicas da atuação da escola.

É nesta contextualização, que os problemas ambientais, não diz respeito apenas à sociedade civil, mas a todos os indivíduos como cidadãos que vive no planeta terra, do qual pertencemos. Por isso, devemos assumir a responsabilidade pelas questões dos efeitos climáticos que assolam na área em estudo e no mundo em geral.

\section{Considerações finais}

No decorrer da pesquisa no campo, os resultados encontrados mostram que o tema da Educação Ambiental, no ensino técnico profissional tem sido abordado de forma fragmentado, o que justificaria a fragilidade de conteúdos que abordam os efeitos climáticos nos programas curriculares. Assim, a sua abordagem na sala de aula dependerá da natureza de cada módulo e a disposição do professor.

Portanto, a implementação da Educação Ambiental no contexto dos efeitos climáticos no Instituto Agrário de Chókwè, ainda apresenta várias lacunas a serem sanadas, tais como: falta de recursos didáticos, falta de recursos financeiros para a capacitação dos professores, a falta de participação das comunidades na vida escolar e na tomada de decisões, falta de tempo para o planejamento e realização de atividades extracurriculares.

Assim, a Educação Ambiental deve funcionar de forma "transversal e interdisciplinar, assegurando a sua inclusão nos programas escolares, priorizando as necessidades básicas sociais, culturais, ambientais, climáticas e da preservação dos recursos naturais, uma vez que estes se podem esgotar, mobilizando a sociedade em geral na perspectiva de desenvolver as atividades económicas que não ultrapassam as capacidades da regeneração dos recursos naturais" (SOARES et al., 2004, p. 42-49). 
Para isso, é urgente a necessidade de desenvolver diversas atividades no âmbito da Educação Ambiental com destaque nos efeitos climáticos, buscando novas maneiras de convivências e agir individual e coletivamente em relação ao meio ambiente, contribuindo a regeneração e a melhoria qualidade de vida dos munícipes da cidade de Chókwè.

É neste contexto, que precisamos de educadores ambientais capacitados e prontos para alterar os currículos do ensino técnico profissional, ensinando constantemente os conteúdos que comtemplam abordagens didáticas teóricas e práticas, tais como:

- Dias de campos, projetos e oficinas pedagógicas para monitorar os efeitos climáticos que possam afetar a qualidade da água, do ar, das florestas com a sua biodiversidade e parques locais;

- Realização de campanha de plantio de árvores, canteiros de mudas, respondendo os resultados dos efeitos climáticos que geram constantemente a destruição das infra-estruturas, morte das pessoas, deslocamentos ambientais e populacionais etc.

\section{Referências}

BRASIL. MEC. PCN Ciências Naturais: Orientações Educacionais para Edcuação no terceiro e quarto ciclos do Ensino Fundamental. Secretaria da Educação Fundamental. Brasília: MEC/SEF, 1998.

BARDIN, Laurence. Análise de conteúdo. Lisboa: Edições 70. 1977.

CHAMBERS, D. Sustainable development: the response from education. Australian country report. Melbourne Graduate School of Education, Australia. 2009.

MOÇAMBIQUE. Diploma Ministerial $\mathbf{n}^{0}$ 25/2011 de 15 de julho n0 32 . [Maputo], 12 de agosto de 2003.

MOÇAMBIQUE. Decretos n. $\mathbf{3 0 / 2 0 1 2}$, de 1 de agosto e $\mathbf{n} . \mathbf{0} \mathbf{1 1 / 2 0 0 3}$, de 25 de março, que aprova o regulamento da lei de florestas e fauna-bravia.

MOÇAMBIQUE. Estratégia Nacional de Adaptação e Mitigação de Mudanças Climáticas, 2013-2025

MOÇAMBIQUE. Lei no 20/97 de 1 de Outubro, n 0. [Maputo], 7 de Outubro de 1997.

FREIRE, Pedagogia da indignação: cartas pedagógicas e outros escritos. São Paulo, Ed. UNESP, (2001).

FAO, Governo De Moçambique, 2009.

GUIMARÃES, M. A dimensão ambiental na educação. 6ª̣ed. Campinas, SP: Papirus, 1995. 
GONZÁLEZ-GUAUDIANO, E. Interdisciplinaridade e Educação Ambiental: explorando novos territórios epistêmicos. In: SATO, M.; CARVALHO, I. C. M. Educação Ambiental: pesquisa e desafios. Porto Alegre: Artmed, 2005.

GADOTTI, M. Pedagogia da Terra: Ecopedagogia e Educação Sustentável. São Paulo: Peirópolis, 2001

HAN, Q. Education for Sustainable Development and Climate Change Education in China. Journal of Education for Sustainable Development. v. 9, n. 1, 2015.

IPCC, Climate Change: The Physical Science Basis. Contribution of Working Group I to the Fourth Assessment Report of the Intergovernmental Panel on Climate Change [Solomon, S., D. Qin, M. Manning, Z. Chen, M. Marquis, K.B. Averyt, M.Tignor and H.L. Miller (eds.)]. Cambridge University Press, Cambridge, United Kingdom and New York, NY, USA. 2007.

Instituto Nacional de Gestão de Calamidades (INGC), 2000.

Instituto Nacional de Gestão de Calamidades (INGC), 2019.

JACOBI, P. R. et al. Mudanças climáticas globais: a resposta da educação. Revista Brasileira de Educação, Vol.16 n46, Rio de Janeiro Jan./Abr. 2011.

KOSATSKY, T. The 2003 European heat waves. Eurosurveillance, v. 10, n.79, 2005.

LÜCKMAN, A. P. Jornalismo e mídia-educação no contexto do aquecimento global. Estudos em Jornalismo e Mídia, Florianópolis, v. 3, n. 2, 2006.

LOUREIRO, C. F. B. Trajetórias e fundamentos da Educação Ambiental. 3 ed. São Paulo: Cortez, 2009.

LOUREIRO, F. AZAZIEL, M E FRANCA, N. Educação ambiental e gestão participativa em unidades de conservação. Rio de Janeiro: Ibase / Ibama. 2003

MARENGO, J. A. Mudanças climáticas globais e seus efeitos sobre a biodiversidade: caracterização do clima atual edefinição das alterações climáticas para o território brasileiro ao longo do século XXI. Brasília: MMA, 2006.

OLIVEIRA, M.J.; VECCHIA, F. A controvérsia das mudanças climáticas globais e do aquecimento global antropogênico: consenso científico ou interesse político? Fórum Ambiental da Alta Paulista, v. 5 , 2009.

SOARES, B.E.C.; NAVARRO, M.A.; FERREIREA, A.P. Desenvolvimento sustentado e consciência ambiental: natureza, sociedade e racionalidade. Ciência e Cognição, v 2, 2004.

VIOLA, E. Impasses e perspectivas da negociação climática global e mudanças na posição brasileira. Breves CINDES, no 30, 2010. 